\title{
Fluorescein pupillary flow in aphakics with intact and spontaneous openings of the vitreous face
}

\author{
H. ZAUBERMAN, Y. YASSUR, AND U. SACHS \\ From the Eye Department, Hadassah University Hospital, Jerusalem
}

SUMMARY The passage of fluorescein dye, injected into the general circulation, from the posterior to the anterior chamber was studied in 60 selected aphakic eyes between 2 days and 4 weeks after an uneventful cataract extraction. In a group of 22 eyes with intact anterior hyaloid, fluorescein was seen to pass only through the pupillary margin, mostly within 20 seconds of the beginning of the eye injection. In 24 eyes with rents in the anterior hyaloid the dye was seen percolating only through the vitreous face openings. No fluorescein passed through the pupillary margin or the peripheral iridectomy in this group of eyes. The appearance time of the dye was delayed to about twice the normal appearance time. In 8 eyes with rents in the anterior hyaloid the dye passed only through the pupillary margin. In 4 eyes with anterior vitreous rents the fluorescein appeared through the anterior vitreous face opening.

From the analysis of the data it appears that the spontaneous breaks in the anterior vitreous face may represent a 'self-cure' of pupillary and iridectomy block by the vitreous in aphakics in a high proportion of cases. It is our impression that 3 peripheral iridectomies and a very tight closure of the wound can prevent the complication of spontaneous breaks of the vitreous face.

Rupture of the anterior hyaloid membrane after uneventful intracapsular cataract extraction is considered to be a common phenomenon both for the round pupil and sector iridectomy techniques (Jaffe, 1969).

The cause of the spontaneous rupture of the anterior hyaloid face remains speculative. Such factors as posterior vitreous separation, haemorrhagic or serous cilio-choroidal detachment, lessening of the tenacious attachment of the vitreous at its base, mechanical damage by the iris pupillary margin, activity of the patient, weakness of the anterior hyaloid, and relative pupillary block have been implicated (Jaffe, 1969). This study was undertaken to investigate whether pupillary block is related to spontaneous breaks in the anterior vitreous face. Using fluorescein dye injected into the circulation, we analysed the passage of the dye through the pupil and the iridectomy to the anterior chamber in 60 aphakic patients who underwent an uneventful cataract extraction.

\section{Materials and methods}

Sixty patients who underwent uncomplicated cataract extraction were selected for this study. The criteria

Address for reprints: Professor H. Zauberman, Eye Department, Hadassah University Hospital, Jerusalem, Israel for selection were their willingness to receive an intravenous fluorescein injection and their good systemic condition. Each patient was examined under the slit lamp between 2 days and 4 weeks after surgery to determine the condition of the vitreous face with regard to gaps in the anterior hyaloid face and the mode of passage of fluorescein into the anterior chamber. Table 1 gives the number of eyes with intact vitreous face and with openings in the vitreous face after cataract extraction. Thirty patients had a round pupil and 1 peripheral iridectomy. In 12 of these there were openings in the vitreous face ranging between 0.25 and $3.2 \mathrm{~mm}$ within the pupillary area. The other $18 \mathrm{had}$ an intact anterior hyaloid.

Thirty patients had sector iridectomies. Of these, 24 had rents in the vitreous face and 6 an intact anterior vitreous. The gaps in the vitreous face in these cases varied between 0.25 and $2.5 \mathrm{~mm}$ in

Table 1 Vitreous face after intracapsular cataract extraction

\begin{tabular}{lll}
\hline & Round pupil & Sector iridectomy \\
\hline Rents in anterior vitreous face & 12 & 24 \\
Intact anterior vitreous face & 18 & 6 \\
\hline Total & 30 & 30 \\
\hline
\end{tabular}


diameter. All the patients had normal intraocular pressures at the time of examination, but 12 of them were receiving daily doses of 0.5 to $1.0 \mathrm{~g}$ of acetazolamide.

To study the passage of fluorescein to the anterior chamber each patient was seated in front of the slit lamp and $2 \mathrm{ml}$ of $15 \%$ fluorescein was quickly injected into the antecubital vein while the pupillary area was screened with a slit of cobalt blue light. The time between the beginning of the injection and the appearance of fluorescein in the pupillary area and iridectomy was recorded. Using a similar technique, Ray and Binkhorst (1966) found that the dye passes through the pupil to the anterior chamber in about $20 \mathrm{~s}$ in normal aphakic eyes, while in the presence of an aphakic pupillary block fluorescein does not appear in the anterior chamber at all or it does only after several minutes very faintly.

\section{Results}

Table 2 shows the pathway and appearance time of fluorescein in the anterior chamber in the 60 aphakic eyes included in this study. In the 22 eyes with intact vitreous face fluorescein was clearly seen percolating from the posterior to the anterior chamber through the pupillary margin. The peripheral iridectomy did not show any flow of fluorescein in this group of eyes. The appearance time of fluorescein was below $20 \mathrm{~s}$ in most of these eyes, the time range being between 11 and $38 \mathrm{~s}$. Fig. 1 shows the passage of dye along the pupillary margin of an aphakic eye with peripheral iridectomy. In the

Table 2 Pathway and time of fluorescein passage to the anterior chamber

\begin{tabular}{|c|c|c|c|c|}
\hline $\begin{array}{l}\text { Characteristics } \\
\text { of anterior } \\
\text { hyaloid and } \\
\text { pupil }\end{array}$ & $\begin{array}{l}\text { Only through } \\
\text { pupillary } \\
\text { margin } \\
\text { (No. of eyes) }\end{array}$ & $\begin{array}{l}\text { Only through } \\
\text { vitreous } \\
\text { rents } \\
\text { (No. of eyes) }\end{array}$ & $\begin{array}{l}\text { Both through } \\
\text { pupillary } \\
\text { margin and } \\
\text { vitreous rents } \\
\text { (No. of eyes) }\end{array}$ & $\begin{array}{l}\text { Peri- } \\
\text { pheral } \\
\text { iridec- } \\
\text { tomy }\end{array}$ \\
\hline $\begin{array}{l}\text { Round pupil } \\
\text { without } \\
\text { anterior } \\
\text { vitreous rent }\end{array}$ & $\begin{array}{l}18 \\
(11 \text { to } 38 \mathrm{~s})\end{array}$ & - & - & - \\
\hline $\begin{array}{l}\text { Round pupil } \\
\text { with anterior } \\
\text { vitreous rent }\end{array}$ & $\begin{array}{l}2 \\
(15-20)\end{array}$ & $\begin{array}{l}8 \\
(40-48 s)\end{array}$ & $\begin{array}{l}2 \\
(10 *-50 s t) \\
(12 *-45 s t)\end{array}$ & - \\
\hline $\begin{array}{l}\text { Sector } \\
\text { iridectomy } \\
\text { without anterio } \\
\text { vitreous rent }\end{array}$ & $\begin{array}{l}4 \\
(16-21 s)\end{array}$ & - & - & - \\
\hline $\begin{array}{l}\text { Sector } \\
\text { iridectomy } \\
\text { with anterior } \\
\text { vitreous rent }\end{array}$ & $\begin{array}{l}8 \\
(12-14 s)\end{array}$ & $\begin{array}{l}16 \\
(45-52 s)\end{array}$ & $\begin{array}{l}2 \\
(10 *-45 s t) \\
(12 *-52 s t)\end{array}$ & - \\
\hline
\end{tabular}

*Early fluorescein passage through pupillary margin.

†Delayed fluorescein passage through anterior vitreous rent.
4 eyes with sector iridectomy in this group the dye could also be seen passing along segments of the iridectomy margins.

In 24 of the 38 eyes with openings in the anterior vitreous face fluorescein could be seen accumulating in fluid pockets within the vitreous body and flowing forward to percolate through the vitreous openings in the anterior face. No dye passage could be detected through the pupillary margin, the peripheral iridectomy, or the sector iridectomy. The appearance time of fluorescein in the anterior chamber was considerably delayed in those eyes in which passage occurred through the pupillary margin and varied between 40 and $48 \mathrm{~s}$. Fig. 2 shows the passage of dye through an opening in the vitreous face. In 10 eyes of the same group with openings in the anterior hyaloid the dye passed only through the pupillary margin within 20 s of injection but not through the vitreous rents. Fig. 3 shows passage of dye along the pupillary margin but not through the vitreous face opening. In 4 eyes with vitreous face rents the passage of dye occurred through both the pupillary margin and the vitreous face openings. In these eyes there was an early passage of fluorescein through the pupillary margin at 10 to $12 \mathrm{~s}$ after the injection and a delayed appearance through the vitreous face gap at 45 to $52 \mathrm{~s}$. Fig. 4 shows the dye percolating through both the pupillary margin and the anterior vitreous face.

\section{Discussion}

The incidence of spontaneous rupture in the anterior vitreous face in aphakics varies in different series between 13.6 and 38\% (Harrington, 1952; Kirsh and Steinman, 1954; Jaffe, 1969). There is a definite relationship between these ruptures in the anterior hyaloid and such postoperative complications as secondary glaucoma, vitreous opacification, pupillary changes, corneal damage, and macular oedema. Yet the mechanism of this important phenomenon has remained obscure. Vannas (1932) speculated that the rupture occurred mainly in eyes in which there was previous vitreous pathology and that the region of the pupillary margin was most frequently affected because of mechanical trauma to this area. Reese (1949) stated that the anterior hyaloid membrane may be torn at the time of the surgical intervention without loss of vitreous. Yet this appeared to be infrequent to Kirsh and Steinman (1954), who examined their cases early after surgery for this purpose, and also to us.

The complication appears to occur mainly within 4 weeks after surgery, although it may happen several months after normal healing (Irvine, 1953). The condition may appear in very sedentary patients 
Fig. 1 Passage of dye along the pupillary margin of an aphakic eye with peripheral iridectomy
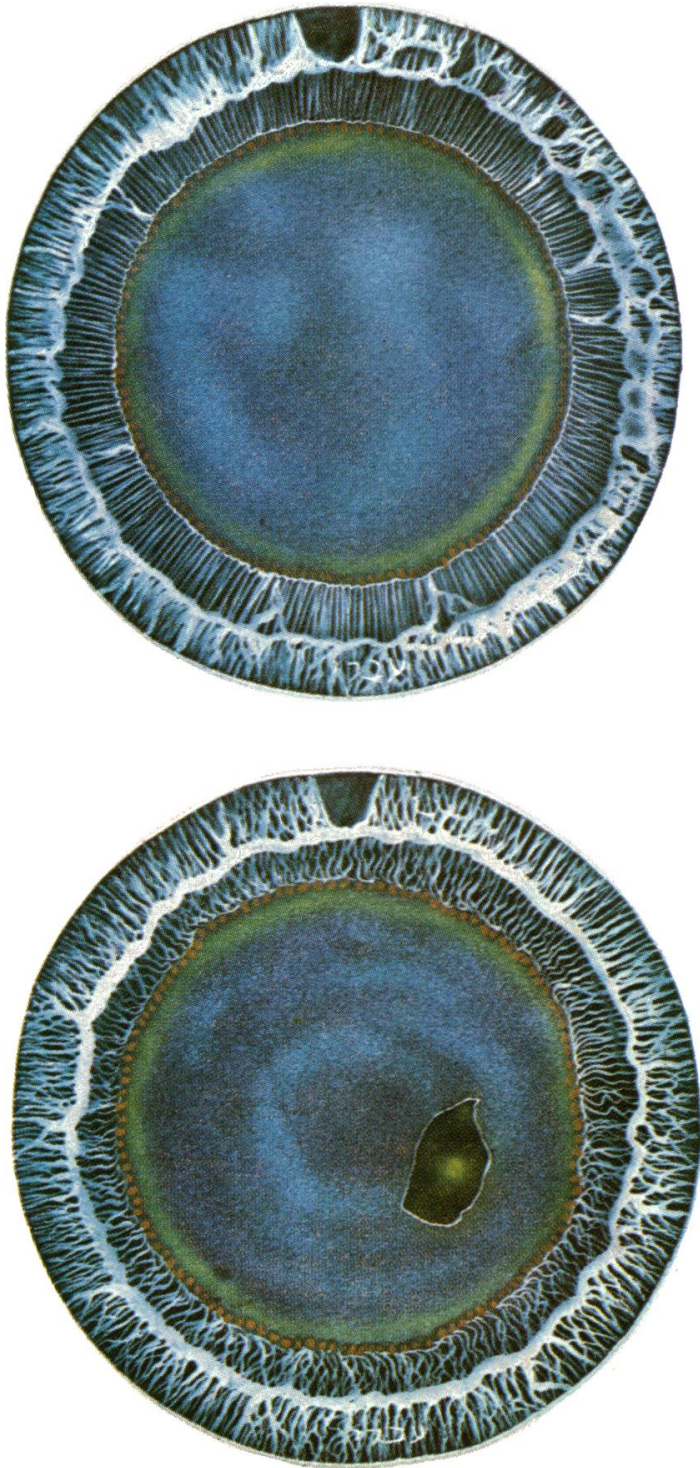

Fig. 3 Passage of dye along the pupillary margin but not through the vitreous face opening

and therefore cannot be linked to vigorous activity. Wound leakage has also been considered as a possible factor (Kirsh and Steinman, 1954).

Our study shows aspects that could be of importance in the understanding of the pathogenesis of spontaneous anterior vitreous rupture after cataract extraction. One is the fact that, in a high proportion of aphakic patients with rents in the
Fig. 2 Passage of dye through an opening in the vitreous face
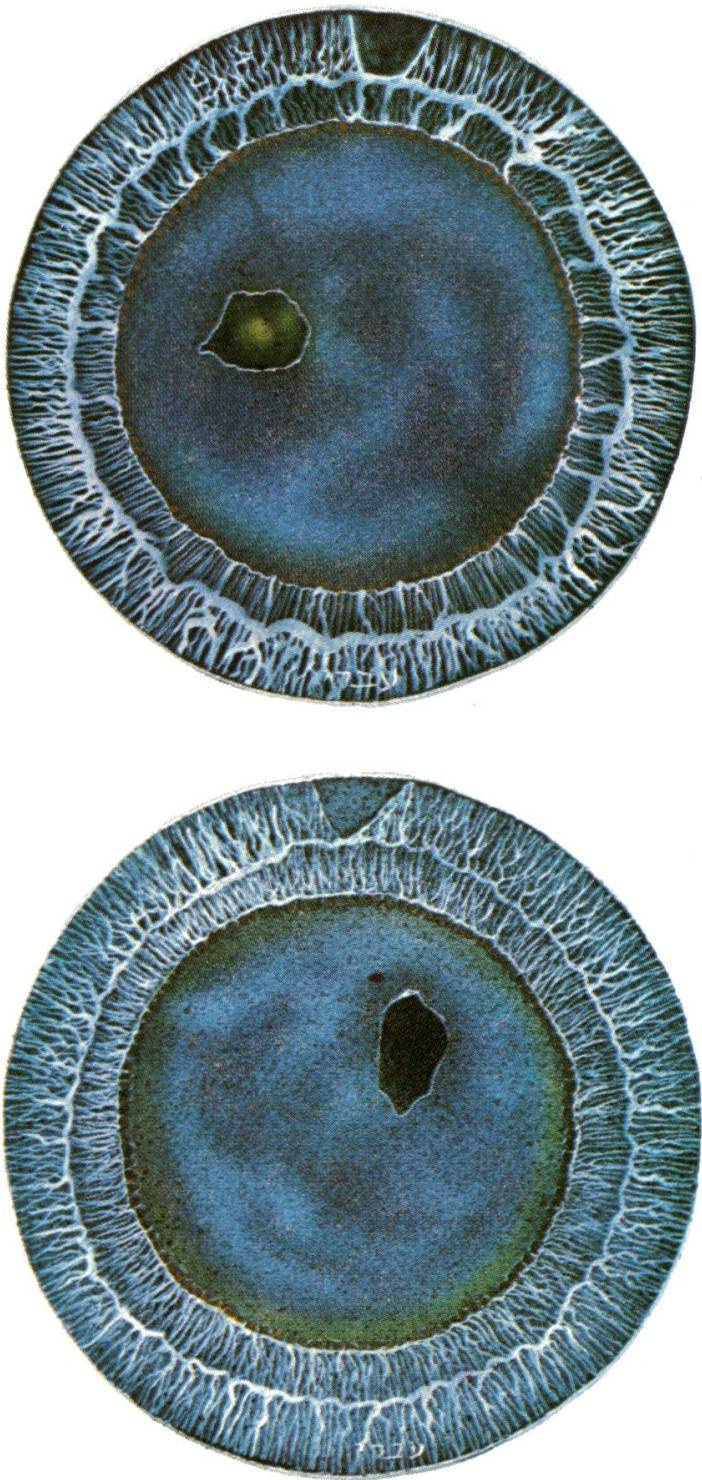

Fig. 4 Dye percolating through both the pupillary margin and the anterior vitreous face

anterior hyaloid, fluorescein passage to the anterior chamber occurs only through the rent in the vitreous face, while no dye is seen percolating through the pupillary margin, the peripheral iridectomy, or sector iridectomy. This phenomenon indicates a block of the pupil iridectomy by the viscoelastic vitreous. The spontaneous ruptures in the anterior vitreous face could then be interpreted as a com- 
pensatory mechanism against pupillary block. Since in the majority of cases the break in the anterior vitreous face occurs in the early postoperative period, it would be reasonable to assume a flow of events in which a small leak in the wound would lead to forward displacement of the vitreous face and a blockage of the pupil and iridectomy. The break in the vitreous face would then be produced by fluid pressure from behind. This way a clinically detectable pupillary block is prevented.

Indirect evidence for this possible mechanism is the observation by Jaffe (1969) in an aphakic patient in which aqueous was shown to penetrate the retrovitreal space through the vitreous substance and not through gaps in the attachment of the vitreous base. Chandler (1951) recognised the importance of inducing surgically an opening in the vitreous face to allow for fluid passage into the anterior chamber in cases of pupillary block leading to malignant glaucoma with an intact vitreous face.

The phenomenon of pupillary and iridectomy block in aphakics could be far commoner than is appreciated, and spontaneous breaks in the anterior hyaloid could represent the tail track of a spontaneous cure. Another aspect of interest in studying the dynamics of fluorescein passage to the anterior chamber is that in eyes with intact vitreous face fluid percolates through the pupil and not through the single peripheral iridectomy.

We are now very particular in sealing the operative wound tightly, and performing 3 peripheral iridectomies. This technique has significantly reduced the incidence of spontaneous breaks in the vitreous face.

\section{References}

Chandler, P. A. (1951). American Journal of Ophthalmology, 34, 993.

Harrington, D. O. (1952). American Journal of Ophthalmology, 35, 1177.

Irvine, S. R. (1953). American Journal of Ophthalmology, 36, 599.

Jaffe, N. S. (1969). The Vitreous in Clinical Ophthalmology, p. 111. C. V. Mosby: St. Louis.

Jaffe, N. S. (1969). The Vitreous in Clinical Ophthalmology, pp. 175-176. C. V. Mosby: St. Louis.

Kirsh, R. E., and Steinman, W. (1954). American Journal of Ophthalmology, 37, 657.

Ray, R. R., and Binkhorst, R. D. (1966). American Journal of Ophthalmology, 61, 480.

Reese, A. B. (1949). American Journal of Ophthalmology, 32, 933.

Vannas, M. (1932). Klinische Monatsblatter für Augenheilkunde, 89, 318. 